\title{
FARMACOLOGÍA PEDIÁTRICA
}

\section{PEDIATRIC PHARMACOLOGY}

\author{
Ma Asunción Peiré García \\ Académica Correspondiente de la Real Academia Europea de Doctores \\ Presidenta Electa de la European Society of Developmental, Paediatric and Perinatal Pharmacology
}

$\begin{array}{ll}\text { Palabras clave: } & \text { Keywords: } \\ \text { Farmacología; } & \text { Pharmacology; } \\ \text { Pediatría; } & \text { Paediatrics; } \\ \text { Farmacología } & \text { Paediatric } \\ \text { pediátrica; } & \text { Pharmacology; } \\ \text { Medicamentos; } & \text { Drugs; } \\ \text { Investigación } & \text { Clinical } \\ \text { clínica; } & \text { Research; } \\ \text { Ensayos clínicos; } & \text { Clinical Trial; } \\ \text { Consentimiento } & \text { Informed } \\ \text { informado. } & \text { Consent. }\end{array}$

La Farmacología pediátrica, definida como la Farmacología de la edad del desarrollo, ha sido a lo largo de la Historia de la Medicina, la disciplina huérfana de pediatras, médicos internistas, farmacólogos, farmacéuticos y otros especialistas pediátricos.

¿Por qué una obra de casi trescientas páginas dedicada exclusivamente al estudio de una disciplina tan singular? Para Galeno, maestro de la Farmacología racional, la edad ya constituía un condicionante terapéutico. Será necesario retomar esta importante reflexión en el siglo XX a raíz de las graves tragedias terapeúticas acontecidas en los niños (como las focomelias debidas a Talidomida o el síndrome del bebé gris por Cloramfenicol).

Debido precisamente a los lamentables accidentes terapéuticos del pasado, y en aras a la protección de la infancia, los niños han devenido "huérfanos terapéuticos" en la certera definición del Dr Harry Shirkey en 1968. Y es que, en efecto, no se investiga con medicamentos con niños por motivos éticos y científicos, y en consecuencia, en las fichas técnicas de los medicamentos los datos pediátricos de dosis, seguridad y eficacia brillan por su ausencia. También el coste en investigación pediátrica contribuye a mantener esta lamentable situación de "orfandad terapéutica".

La Farmacología pediátrica, en palabras del Dr Summer Yaffe, es una "disciplina sofisticada". No resulta tarea fácil adaptar los conocimientos de la Farmacología general a las circunstancias fisiológicas y patológicas de un ser en constante desarrollo y maduración como es un niño. Por tanto, no se trata de una mera adaptación de las dosis del adulto al menor, como tampoco trocear comprimidos para su conversión en un jarabe de agradable sabor. Existen unas diferencias farmaco-

\author{
Autor: Ma Asunción \\ Peiré García \\ ISBN: 978-987-4922-23-6 \\ Edición: Primera \\ Año de edición: 2019 \\ Páginas: $274 \mathrm{pp}$ \\ Editorial: Ediciones \\ Journal, Buenos Aires, \\ Argentina
}

cinéticas y farmacodinámicas que convierten al niño en un ser único. Y es que, como afirmaba Rousseu, el niño no es un "adulto en miniatura".

El presente Tratado pretende poner remedio a la situación de orfandad terapéutica de los niños con los medicamentos en aras a procurar su bienestar y desarrollo. Constituye por tanto una obra de consulta para pediatras y profesionales que tratan niños (como internistas, anestesiólogos pediátricos, intensivistas pediátricos, farmacólogos, farmacéuticos, entre otros) y también para la Industria farmacéutica (dado que dedica además una sección al estudio de las bases de la investigación clínica con menores).

La obra que se comenta es fruto de un vasto trabajo de investigación, síntesis y sistematización de todos los aspectos relacionados con esta novedosa especialidad, abarcando tanto aspectos de Farmacología básica pediátrica como la Terapéutica, pasando por la Investigación clínica con menores y sus condicionantes éticos y jurídicos.

Al ser obra de una única autoría, se logra una coherencia y equilibrio de lectura entre las diversas partes de la misma, por lo que no existen diferencias de estilo entre los distintos capítulos, a pesar de tratarse de temas muy dispersos pero coordinados bajo el mismo paraguas protector de su Autora.

Aventurarse a escribir un Tratado monográfico de casi 500 páginas (versión en manuscrito) en sus diversas vertientes (médica, farmacéutica, ética y jurídica) es, sin duda, una obra titánica. Ahora bien, para la Autora constituye una obligación moral a la vez que un privilegio el haber tratado de sistematizar y poner orden en una materia tan amplia y dispersa como la que nos ocupa. 
El conocimiento y estudio de las bases de la Farmacología Pediátrica contenidas en el presente manual, no solo incrementa la dignidad intelectual del profesional, sino que también conlleva mayor libertad personal e intelectual, de modo que, convenimos con el Prof Laín Entralgo, quien conoce, puede elegir con mayor tranquilidad y acierto.

Con objeto de simplificar y dotar de coherencia la obra, se ha considerado conveniente sistematizar su estudio en tres secciones:

\section{-Sección 1: Bases de la Farmacología del desarrollo}

-Sección 2: Principios de la Terapéutica en Pediatría

-Sección 3: Aspectos éticos y legislativos en Investigación pediátrica.

La Sección 1 considera las Bases de la Farmacología del Desarrollo. Como pilar básico, se dedica el primer capitulo al estudio de la Farmacocinética pediátrica. En el mismo, se hace una especial mención a la ontogenia de las enzimas implicadas en el metabolismo de los medicamentos. Ello explica, a título ejemplificativo, un aumento de la toxicidad en recién nacidos por Cloramfenicol (debido a la ausencia de detoxificación hepática por ácido glucurónico) o por el contrario, una disminución de la toxidad a dosis elevadas por Paracetamol en niños pequeños (debido precisamente a la ausencia de vías metabólicas que conllevan la generación de metabolitos intermedios hepatotóxicos así como a la existencia de otros mecanismos de compensación metabólica, como una mayor concentración hepática de glutatión o sulfato).

La peculiar Farmacodinamia se estudia en el siguiente capítulo debido a que muchas respuestas anómalas a fármacos son debidas a la ontogenia de los receptores farmacológicos. A modo de ejemplo, puede citarse el caso de la excitación paradójica del neonato (con provocación de convulsiones) ante la administración de benzodiacepinas (con supuesto efecto sedante) debido a que el receptor GABA a edades muy tempranas no se comporta como un receptor inhibitorio, sino todo lo contrario, excitatorio (por inversión del sentido de flujo del canal de cloro). Como dato curioso, merece la pena citar el caso de la ineficacia en los niños pequeños de los antidepresivos tricíclicos y de los inhibidores de la MAO (por inmadurez del sistema noradrenérgico) y en cambio mejor respuesta a los inhibidores de la recaptación de serotonina (ISRS) porque el sistema serotoninérgico sí que está desarrollado en la primera infancia.

Las vías de administración de medicamentos y las formas farmacéuticas merecen una especial atención en esta sección. Baste recordar por ejemplo la toxicidad de la vía cutánea en un niño pequeño. En cuanto a la galénica, se insiste en los peligros de los excipientes en Pediatría: contraindicación de benzoatos (por riesgo de kernicterus), sulfitos (relacionados con la aparición de casos de asma) o etanol (por su hepato y neurotoxicidad). Además, excipientes de apariencia inofensiva como la sacarosa, actualmente están en desuso debido a la auténtica epidemia de obesidad infantil y también por su riesgo cariogénico. En este sentido, se puede mencionar, a título anecdótico, lo descrito en su diario por el médico personal del Delfín de Francia Luis XIII, el Dr Jean Héroard, quien responde a una pregunta formulada el 11 de Marzo de 1605 por el joven monarca:"de savoir si le sucre luy faira jeunir les dents. Je luy dis que non mangé avec la poire. E come cela? Dict-il mentant un doigt dans le sucre. Oui M, disje, comme cela. S' en garde et le mange avec la poire. Il craignoit que ses dents ne se gatassent".

Por primera vez al monarca se le administraba un medicamento en una solución azucarada (y no en leche de oveja o de cabra), con lo que la caries acababa de comenzar (problema que además tendría que soportar desde temprana edad y durante toda su vida).

En dicho capítulo se hace una reflexión sobre la necesidad de cambiar de paradigma sobre las formas orales en niños, siendo preferibles en la actualidad las formas sólidas (como mini comprimidos orodispersables) en detrimento de las líquidas (por los riesgos de los excipientes y problemas de conservación tales como temperatura.

En dicho capítulo también se hace una especial mención a las fórmulas magistrales. En efecto, todavía muchas enfermedades raras no disponen de una galénica pediátrica apropiada, y es por ello que la formulación magistral, diseñada a la medida del pequeño paciente, será como un "traje a medida". En este sentido merece la pena recordar las palabras del Dr Marañon que se pronunciaron en un sentido similar: "La necesidad de que el médico no emplee sistemáticamente el específico, olvidando la fórmula magistral. Tiene aquel algo de traje de bazar, que lo pueden llevar todos, pero a ninguno sienta exclusivamente; así como la fórmula bien meditada equivale al traje hecho a medida de la dolencia y del enfermo mismo"

Fruto de lo explicado en los capítulos precedentes, se entiende que la Farmacovigilancia en Pediatría adquiera unos tintes propios que la singularizan respecto del adulto. Así, muchos medicamentos interfieren con el crecimiento y el desarrollo (como los corticoides, el Montelukast), otros producen efectos a largo plazo (como el Metilfenidato o los anestésicos generales administrados de forma prolongada en niños menores de cuatro años), mientras que otros presentan una idiosincrasia propia en la niñez que no se observa en la edad adulta (como la toxicidad cutánea por Lamotrigina). Con todo, no hay que olvidar que hasta el $54 \%$ de las reacciones adversas en Pediatría son debidas a analgésicos opioides y a agentes anestésicos.

El capítulo de Interacciones farmacológicas no olvida tampoco las interacciones con las plantas medicinales. Muchos padres no son conscientes que muchos productos "naturales" y de inofensiva apariencia pueden provocar serias interacciones conllevando a una pérdida de eficacia o toxicidad de los medicamentos. Baste recordar las importantes interacciones con el Hipérico o Hierba de San Juan.

Dado que los medicamentos en los niños habitualmente se administran con la comida, se ha considerado conveniente incluir un capítulo sobre interferencia 
de los medicamentos con los alimentos. En dicho capítulo además se hace una especial mención a la nutrigenómica.

Las interferencias con los métodos analíticos y con la clínica son objeto de estudio breve en el capitulo que prosigue.

La hora de administración de los medicamentos es un factor importante que puede condicionar la respuesta terapéutica. Por ello, y dado que esta información no se encuentra en los tratados de farmacología habituales, se incluye también un capítulo dedicado a la nofarmacología. En el mismo se analizan tanto la cronocinética como la cronodinamia, haciendo una especial referencia a los medicamentos oncológicos.

Termina dicha sección con un capítulo dedicado a la Monitorización de los principales fármacos en Pediatría.

Los principios de la Terapéutica en Pediatría se analizan en la Sección 2 del libro. Abre esta sección el importante capítulo sobre Dosificación de medicamentos en Pediatría como preámbulo para el estudio del niño enfermo. Y es que precisamente los medicamentos se administran a niños enfermos, y por ello es preciso conocer como responden los fármacos en caso de insuficiencia hepática, renal, cardíaca, dieta inadecuada (y alteración del citocromo p450) o la inflamación. A modo de ejemplo se puede citar el como la inflamación provoca un menor aclaramiento del Midazolam, por lo que habrá que ajustar la dosis de éste. Y no hay que olvidar que un acto quirúrgico per se causa inflamación, con lo que habrá que extremar las precauciones para evitar alcanzar dosis tóxicas.

Se ha considerado oportuno dedicar un capítulo a la Farmacogenética. En el mismo se estudia la ontogenia de las enzimas y proteínas implicadas en la respuesta terapéutica a los medicamentos.

El estudio del feto y del paso de fármacos a través de la leche materna se exponen en dos capítulos consecutivos, para terminar esta sección con un capítulo dedicado al estudio de las Enfermedades Raras y Medicamentos Huérfanos.

Finalmente, en la Sección 3 se consideran los Aspectos éticos y legislativos en Investigación Pediátrica. El pilar básico lo constituye el diseño ético y científico del Ensayo Clínico, capitulo que inicia la sección y que viene completado por la correcta obtención del Consentimiento Informado en menores de edad en el capítulo que le sigue. Como se sabe, los niños, al ser menores de edad, legalmente no pueden otorgar por sí mismos el consentimiento para acceder a participar en un ensayo clínico: son sus padres o tutores (representantes legales) quienes lo otorgan, y el menor firmará su acuerdo si tiene doce años o más. Con todo, siempre debe respetarse la decisión del menor, con independencia de su edad.

Las consideraciones éticas encuentran su correlato legal en las disposiciones normativas que se analizan en el siguiente capítulo. En el mismo se analizan los requisitos legales de cualquier investigación científi- ca con menores, así como los incentivos económicos para que las compañías farmacéuticas dediquen recursos económicos, humanos y técnicos a desarrollar medicamentos pediátricos. Pero es que, como decía nuestro Premio Nobel, Don Santiago Ramón y Cajal, "más que escasez de medios, hay miseria de la voluntad". Los condicionantes económicos para investigar medicamentos en los niños no puede ser por más tiempo, en pleno siglo XXI, la causa de orfandad terapéutica del niño.

También la ley se encarga de regular el empleo de medicamentos utilizados al margen de lo autorizado en las fichas técnicas. Se dedica para ello un capítulo sobre medicamentos "off label" y "unlicensed drugs" con el objeto de arrojar luz sobre un tema tan controvertido. Entre el $70-90 \%$ de los medicamentos empleados en hospitales pediátricos no tienen una autorización de uso pediátrico, ya sea porque no tiene aprobada la indicación, dosis, vía de administración, indicación u otros requisitos para su empleo en niños. Hay que recordar, que el uso de esta práctica no implica en modo alguno que se trate de un uso ilegal o inapropiado: simplemente, se emplean en condiciones distintas de lo autorizado en las fichas técnicas porque la compañía farmacéutica no ha actualizado las mismas. En este sentido, merece la pena recordar que cuando los Tribunales enjuician casos de responsabilidad médica por daño, valoran principalmente si la práctica asistencia se ha ajustado o no a la "Lex artis ad hoc"; y no tanto sobre si se empleó un medicamento autorizado o no en la Ficha Técnica.

Los niños tienen los mismos derechos que los adultos a recibir medicamentos biológicos. Para ello se dedica un capítulo a esta materia, en el que además se hace una comparación con los medicamentos biosimilares.

Antes de abordar el estudio de los distintos tipos de Ensayos Clínicos, se ha considerado conveniente incluir un capítulo dedicado a los estudios preclínicos. En el mismo, se estudian los requisitos previos antes de diseñar un ensayo clínico pediátrico, como pueden ser las características físico-químicas del medicamento, los estudios de toxicidad y mutagénesis, así como las importantes guías internacionales sobre estudios en animales jóvenes.

El último capítulo del presente libro se dedica al estudio de los Ensayos Clínicos especiales en oncología, SIDA, embarazo, lactancia y enfermedades raras.

En conclusión, el presente libro pretende sentar las bases éticas y científicas de la Terapéutica farmacológica del niño. Se trata de un libro que sin embargo está abierto a futuras aportaciones de otros profesionales que con toda seguridad lo enriquecerán con su crítica constructiva. Con todo, posee una estructura lo suficientemente sólida que permitirá, en modesta opinión de su autora, resistir el paso del tiempo. Como afirmaba la Premio Nobel la Dra Rita Levi-Montalcini, "las afirmaciones científicas no son dogmáticas; son progresivamente más precisas a medida que avanza la investigación". Es por ello que el presente trabajo de revisión y sistematización de una materia tan vasta y compleja como la que nos ocupa, estará sometido a continuas revisiones y actualizaciones. $\mathrm{Y}$ es que como afirmaba 
el filósofo de la ciencia Karl Popper, "los que no están dispuestos a exponer sus ideas a la aventura de la refutación, no toman parte en el juego de la ciencia".

No hay que olvidar que actualmente los medicamentos han devenido singulares bienes de consumo, que vienen envueltos en un envase ético cuyo contenido consiste en un extracto purificado de los últimos avances científicos en Farmacología Pediátrica. Y es que los niños siguen esperando el poder disponer de medicamentos adecuados a sus necesidades terapéuticas y preferencias. El conocimiento de la Farmacología Pediátrica se aplicará pues, con rigor científico, pero también con compasión, al ser humano más necesitado de protección: el niño.

Concluimos este trabajo con la importante reflexión de Hipócrates descrita en su Tratado sobre la Decencia aconsejando a los médicos a conocer los remedios que aplicaban a sus pacientes: "Lleva bien aprendidos los medicamentos y sus propiedades simples y compuestas - supuesto que tienes en la mente los medios de curación de las enfermedades - y recuerda sus diversas modalidades, las proporciones y la manera de como se comportan en cada caso. Esto, en Medicina, es principio, medio y fin".

\section{AGRADECIMIENTOS}

La Autora expresa su sincero agradecimiento al Excmo. Sr. D. Enrique Casado de Frías por su amable prólogo al libro. Asímismo, agradece al Excmo. Sr. D. Manuel Serrano Ríos y al Excmo. Sr. D. Pedro Sánchez su total confianza en que este libro viera la luz.

\section{DECLARACIÓN DE TRANSPARENCIA}

El autor/a de este artículo declara no tener ningún tipo de conflicto de intereses respecto a lo expuesto en la presente revisión. 